\title{
CARACTERIZAÇÃO E AVALIAÇÃO DO EFEITO DE INCORPORAÇÃO DE NANOPARTICULAS DE PRATA EM COMPÓSITOS DE GRAFITE VISANDO SUA APLICAÇÃO EM BIOSSENSOR ENZIMÁTICO ELETROQUÍMICO
}

\author{
V. M. SANTOS ${ }^{1}$, R. S. A. RIBEIRO ${ }^{1}$, H. A. OLIVEIRA ${ }^{1}$, E. M. ALHADEFF ${ }^{2}$ e N. I. \\ BOJORGE RAMIREZ ${ }^{1 *}$ \\ ${ }^{1}$ Universidade Federal Fluminense, Departamento de Engenharia Química e de Petróleo \\ ${ }^{2}$ Universidade Federal do Rio de Janeiro, Escola de Química \\ Email para contato: nbojorge@id.uff.br
}

\begin{abstract}
RESUMO - O objetivo deste trabalho é determinar o efeito da incorporação de nanoparticulas de prata (AgNPs) estabilizadas em borohidreto de sódio em compósito Grafite/Epóxi (GEC) e sua aplicação em biossensor eletroquímico a base de Horseradish peroxidase (HRP) como dispositivo de medição e monitoramento da concentração de etanol biocombustível em processos fermentativos. A enzima álcool-oxidase oxida álcoois de baixo peso molar utilizando como receptor de elétrons o oxigênio molecular. Para determinar o empenho dos biossensores foram testados em voltametria cíclica a diferentes concentrações de etanol e velocidades de varredura de 10 a $100 \mathrm{mV} / \mathrm{s}$. A incorporação das AgNPs melhorou as propriedades elétricas, ópticas e dielétricas dos compósitos atuando como condutoras entre o grafite, e elevou a condutância elétrica do compósito. A utilização de enzimas nos biossensores tem se tornado uma alternativa interessante por apresentar um menor gasto em pré-tratamentos além do aumento da especificidade.
\end{abstract}

\section{INTRODUÇÃO}

A nanotecnologia traz novas possibilidades para a construção de biossensores auxiliando no desenvolvimento de sensores eletroquímicos. Materiais em nanoescala têm sido utilizados para promover uma ligação direta entre as enzimas e o eletrodo de superfície, a promover a reação eletroquímica, impor nanoreconhecimento para biomateriais e para amplificar o sinal de evento de reconhecimento. Os métodos atuais de detecção como cromatografia gasosa, cromatografia líquida de alta performance (HPLC) são relativamente caros e de alta complexibilidade, além de não permitirem facilmente a monitoração contínua, por isso, metodologias alternativas precisam ser consideradas (Alhadeffe e Bojorge, 2011; Santana et al., 2014).

Nanomateriais aliados a transdutores eletroquímicos abrem excelentes perspectivas para concepção de novos sistemas de detecção a fim de melhorar o desempenho das análises bioanaliticas (Cammann, 1987). As nanopartículas metálicas têm fornecido blocos promissores para a realização de biossensores eletroquímicos, devido à sua biocompatibilidade e tecnologicamente importante combinação de propriedades, tais como a 
área de superfície elevada, boa condutividade elétrica propriedades e estabilidade química (Santana et al., 2014; Wang, 2005).

Além disso, a integração dos nanomateriais em dispositivos eletroquímicos oferece a uma fácil portabilidade e uso aliado ao seu baixo custo, devido à facilidade de miniaturização tanto do material e ao sistema de transdução. A síntese de nanopartículas de prata é empregada para ter um melhor controle sobre o tamanho das partículas, distribuição, morfologia, pureza, quantidade e qualidade. A redução química é o método mais frequentemente utilizado para a preparação de nanopartículas de prata, como dispersões coloidais estáveis em água ou solventes orgânicos (Ahmad, 2007). A síntese de nanopartículas por métodos de redução químicos são muitas vezes executadas na presença de estabilizadores, de modo a evitar a aglomeração indesejada da solução coloidal de nanopartículas

A tecnologia de imobilização enzimática tem desempenhado um papel importante neste sentido, não só ajuda na fixação do componente para o transdutor, mas também ajuda a estabilizar-lo para reutilização. O material biológico pode ser imobilizado diretamente sobre o transdutor ou em membranas, que podem ser subsequentemente montadas no transdutor (Garcia, 2010; Ahmad, 2007). A escolha do método de imobilização depende de muitos fatores, tais como a natureza do elemento biológico, o tipo de transdutor utilizado, as propriedades físico-químicas da substância a analisar e as condições de funcionamento em que o biossensor está a trabalhar. Os reagentes consumidos ou produtos formados podem ser detectados ou medidos através de transdutores-

O objetivo principal deste trabalho consiste em caracterizar o efeito da incorporação de AgNPs em compósitos GEC para a construção de biossensores de bioetanol, visando aumentar a sensibilidade eletroquímica do dispositivo para a detecção de etanol.

\section{METODOLOGIA}

Os reagentes utilizados no estudo foram todos preparados de maneira analítica e o solvente utilizado foi água destilada. Para análise da resposta eletroquímica por meio de voltametria cíclica foi utilizado um potenciostato com módulo de espectroscopia de impedância eletroquímica integrada marca Ivium, modelo CompactStat (Ivium Technologies, The Netherlands) controlado por um computador via software dá IviumSoft. Essas experiências foram realizadas numa célula eletroquímica estática a $25^{\circ} \mathrm{C}$ a diferentes velocidades de varredura $(10,30,40,75,100 \mathrm{mV} / \mathrm{s})$. A célula eletroquímica é composta por três eletrodos: Eletrodo de Platina, eletrodo de referência $\mathrm{Ag} / \mathrm{AgCl}(3 \mathrm{M})$ e o eletrodo de trabalho onde o compósito(GEC) impregnados de nanopartículas de prata (AgNP-GEC) é fixado com ajuda de uma espátula em uma cavidade de $3 \mathrm{~mm}$ de diâmetro x $3 \mathrm{~mm}$ de profundidade constituida na parte superior do biossensor. Como solução eletrolítica padrão utilizou-se uma solução aquosa de $\mathrm{K}_{4} \mathrm{Fe}(\mathrm{CN})_{6} 10 \mathrm{mM}$, em $\mathrm{KCl} 3 \mathrm{M}, \mathrm{pH}$ 7.0. As condutividades eléctricas dos compostos foram testadas utilizando a técnica de dois eléctrodos, que consiste em pastilhas de composição conhecida de elementos do compósito o qual é fixada com a ajuda de um suporte de Teflon e determina a resistência eléctrica do compósito. Os testes foram realizados utilizando um medidor de banco Manaus ICEL MD 6700 acoplado a um computador. 


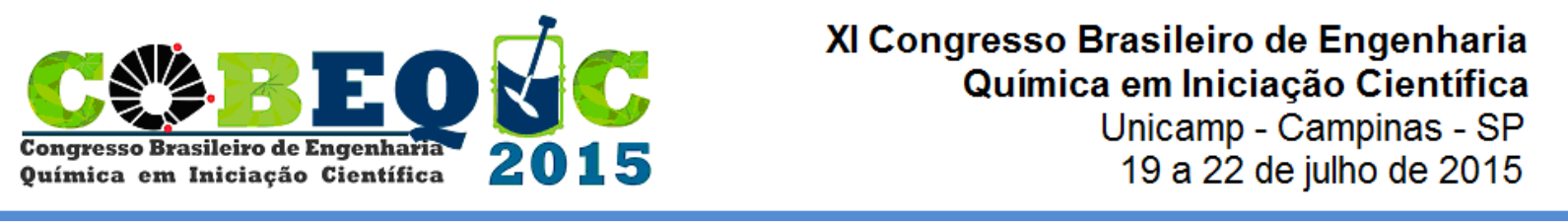

\subsection{Sínteses das nanopartículas de prata}

O procedimento empregado para obtenção das AgNPs foi o seguinte:

Uma solução de $30 \mathrm{ml}$ de borohidreto de sódio $0,0020 \mathrm{M}$ foi preparada frescamente, e com ajuda de uma proveta graduada a solução foi vertida em um erlenmeyer de $200 \mathrm{ml}$, o qual foi mantido em um banho de gelo e deixou-se esfriar por cerca de 20 minutos.

Sob agitação foi adicionado gota a gota (cerca de $2 \mathrm{ml}$ ) uma solução de $\mathrm{AgNO}_{3}$ 0,001M á solução de borohidreto de sódio contida no erlenmeyer, até que se formasse um coloide amarelo escuro. As nanopartículas de prata que se formaram foram estabilizadas por uma camada protetora de íons borohidreto, o que garantiu sua estabilidade e evitou a aglomeração das nanoparticulas de prata. Após a formação do coloide manteve-se sob agitação em banho de gelo por $5 \mathrm{~min}$.

Após a obtenção da solução de nanopartílas adicionou-se a 150mg de grafite puro, onde se homogeneizou e deixou em processo de secagem em estufa a $100^{\circ} \mathrm{C}$ por 12 horas. Após a obtenção do compósito grafite/AgNPs adicionou-se Epóxi na proporção 60/40 (w/w) respectivamente, e foi adicionado a superfície do sensor onde deixou-se secar para posterior análise eletroquímica comparativa por meio de voltametria cíclica.

\subsection{Aplicações de enzima HRP no sensor eletroquímico-}

A partir da solução enzimática composta por 286 unidades de enzima Alcool Oxidase (AOD) e 2640 uunidades de enzima Horseradish peroxidase (HRP) já pronta, foram depositados $10 \mu \mathrm{L}$ na superfície do eletrodo que permaneceu armazenado à $4^{\circ} \mathrm{C}$ por 12 horas. A análise eletroquímica comparativa foi feita por meio de voltametria cíclica numa célula contendo $50 \mathrm{~mL}$ de solução de $\mathrm{K}_{4} \mathrm{Fe}(\mathrm{CN})_{6} 10 \mathrm{mM}$ em $\mathrm{KCl}$ 0,01 M diluído em agua destilada com adição de $1 \mathrm{~mL}$ de solução de etanol 95\%.

\section{RESULTADOS E DISCUSSÃO}

$\mathrm{Na}$ análise da aplicação do uso de nanopartículas de prata no compósito de grafite/epóxi observou-se um aumento da condutividade e uma maior sensibilidade a concentração da solução. Utilizando-se do software e potentiostato Ivium-n-Stat para análise voltimétrica, foram testadas velocidades de varredura que variaram de $10 \mathrm{mV} / \mathrm{s}$ a $100 \mathrm{mV} / \mathrm{s}$ no sensor eletroquímico com nanopartículas de prata. Diversos experimentos foram realizados para obter os voltamogramas cíclicos deste sensor em solução de $\mathrm{K}_{3}\left[\mathrm{Fe}(\mathrm{CN})_{6}\right]$, $\mathrm{pH} 7.0$ a diferentes velocidades de varredura $(10,30,40,75,100 \mathrm{mV} / \mathrm{s})$ mostrando os perfis com picos bem definidos, conforme mostra a Figura 1: 
Figura 1 - Voltamogramas cíclicos do sensor a diferentes velocidades de varredura em solução de $\mathrm{K}_{3}\left[\mathrm{Fe}(\mathrm{CN})_{6}\right] \quad 0,001 \mathrm{M}$

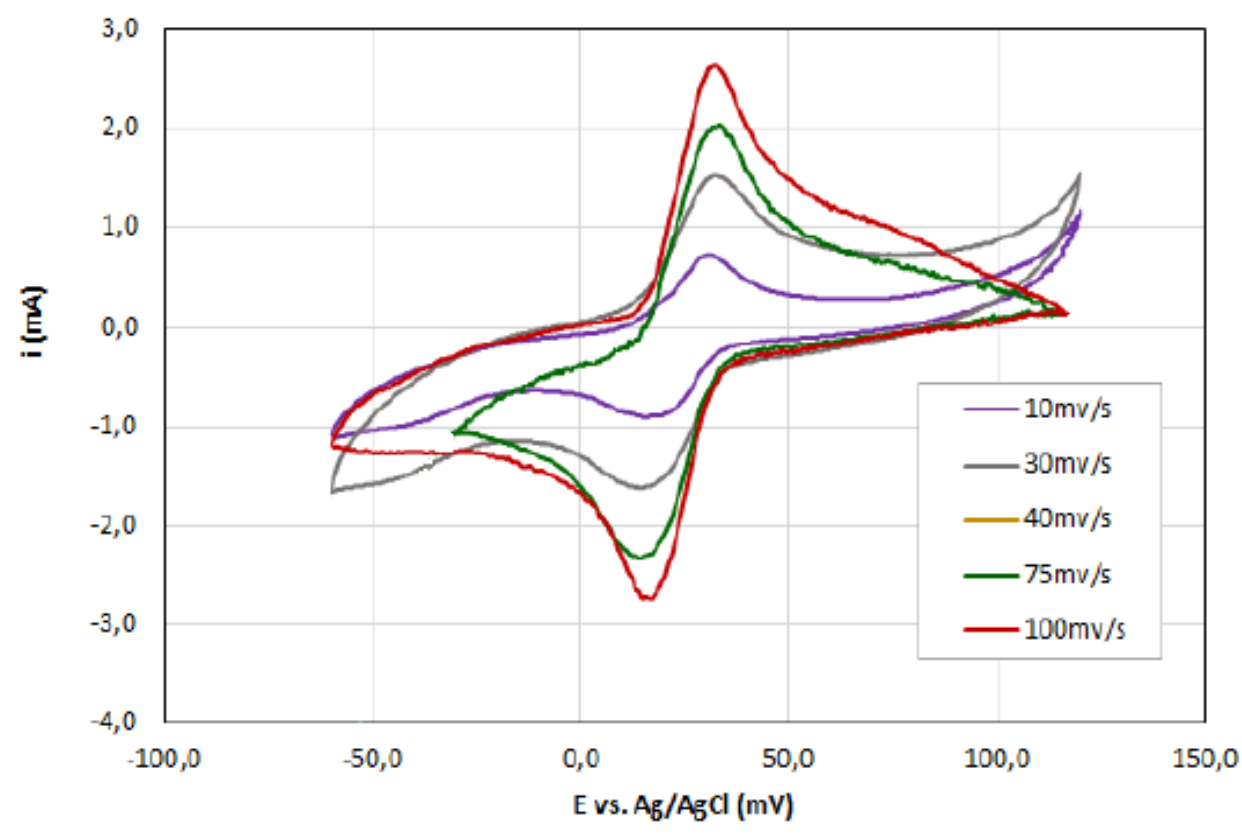

Quanto a aplicação das nanopartículas observou-se que o sistema de processo redox é quase reversível com $\Delta \mathrm{Ep}=50 / \mathrm{n} \mathrm{mV}$, bem próximo de um sistema completamente reversível $(\Delta \mathrm{Ep}=57 / \mathrm{n} \mathrm{mV})$ e os picos de corrente linear aumentam proporcionalmente com a $v^{1 / 2}$. Na relação das correntes Ipa/Ipc obteve-se uma média ligeiramente superior a 1 indicando também que se apresenta muito próximo de um sistema reversível (Ipa/Ipc=1). Neste caso a reação eletroquímica para este sistema será controlada tanto pela etapa de transferência de massa como pela etapa de transferência de carga.

$\mathrm{Na}$ imobilização enzimática quando a peroxidase é imobilizada numa superfície do eléctrodo, a forma oxidada da enzima, que é formada na reação com o peróxido, pode ser reduzida para a sua forma nativa por uma transferência direta ou mediada de elétrons. Etanol atua como um mediador de elétrons no sistema. Com base nestes princípios biossensores para compostos etanoicos foram desenvolvidos onde HRP foi imobilizada em eletrodos de grafite/epóxi sólidos. O mecanismo de enzima envolvida num biossensor baseado na peroxidase para detecção consiste na oxidação de moléculas de enzima por peróxido de hidrogénio, seguida da sua redução por composto etanoico. Esta última redução converte etanol para aldeído, no qual o elétron ativo pode ser reduzido na superfície do eletrodo. A corrente de redução é proporcional à concentração de etanol na solução.

Assim como no sensor eletroquímico com nanoparticulas de prata, de modo a obter uma comparação da condutividade eletroquímica em um biossensor com e sem a aplicação de enzimas foram testadas velocidades de varredura que variaram de $10 \mathrm{mV} / \mathrm{s}$ a $100 \mathrm{mV} / \mathrm{s} \mathrm{em}$ uma solução de $50 \mathrm{~mL}$ de $\mathrm{K}_{4} \mathrm{Fe}(\mathrm{CN})_{6} 10 \mathrm{mM}$ em $\mathrm{KCl}$ 0,01 M diluído em agua destilada com adição de $1 \mathrm{~mL}$ de solução de etanol 95\%, pH 7. Uma outra bateria de testes permitiram obter os voltamogramas cíclicos do biossensor sem enzimas e os respectivos voltamogramas cíclicos do biossensor com as enzimas imobilizadas mostrando seu efeito sinérgico. Como se vê na comparação a seguir na Figura 2: 
Figura 2 - Respostas eletroquímicas do biossensor com: (A) enzima HRP imobilizada e (B) sensor sem aplicação de enzima HRP
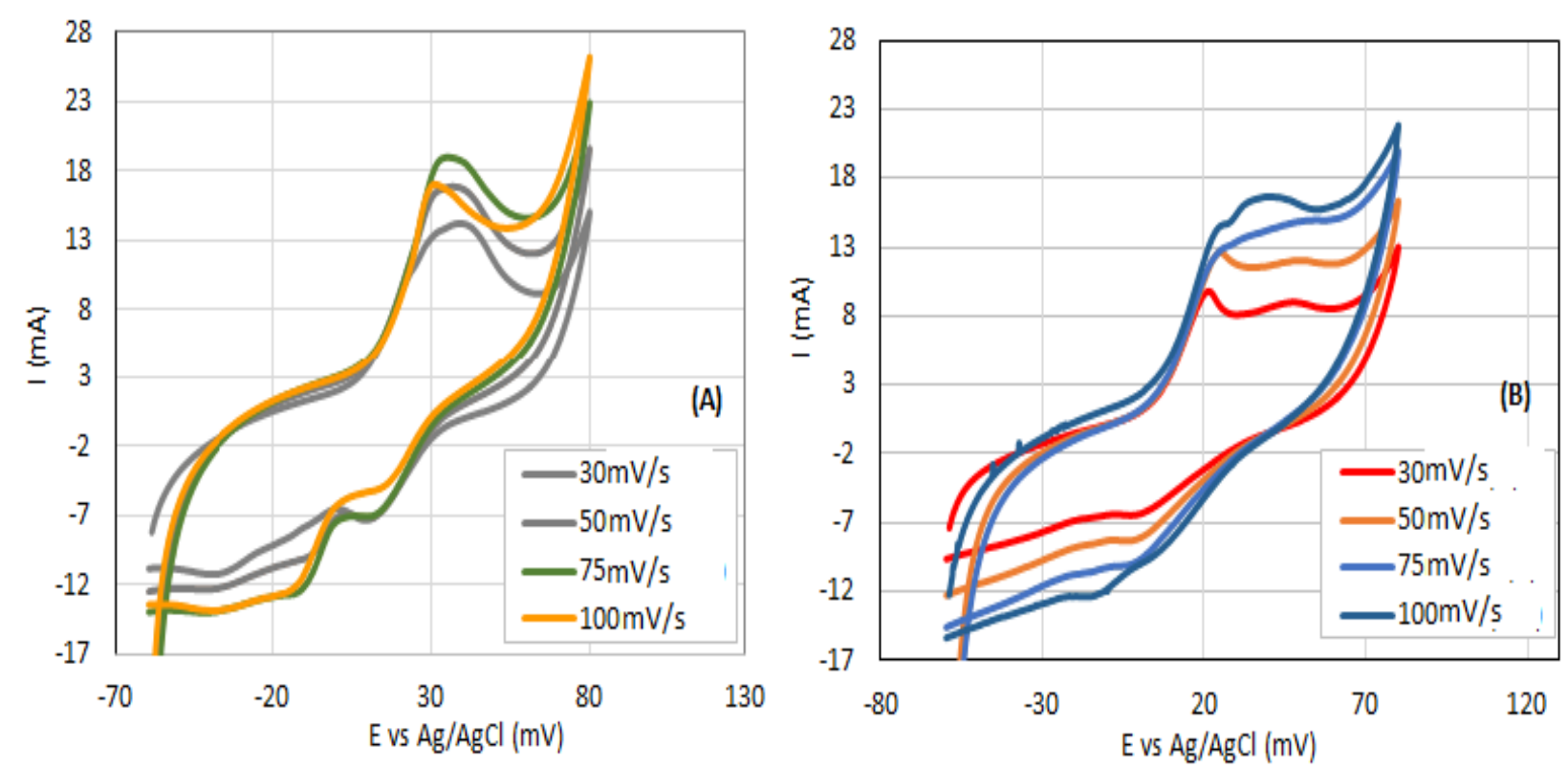

A utilização de enzimas na confecção de biossensores, para análise de etanol, se mostrou eficaz gerando picos Ipa e Ipc bem definidos possibilitando através do uso da equação de Nerst obter a concentração de etanol presente na solução. Mas seu sistema ainda não se encontra reversivel, o que ainda deve ser trabalhado.

Para que uma reação seja reversível a corrente de pico deve variar linearmente com a raíz quadrada da velocidade de varredura, a reversibilidade do sistema esta ligada a troca de eletrons entre a solução e eletrodo pelos processos de oxidação e redução, o qual nos garante que o sensor esta em perfeitas condiçoes de ser aplicado ao monitoramento de processos.

Com objetivo da caracterização da solução de AgNPs foi realizado uma análise por espectroscópia por energia dispersiva (EDX), no qual se verificou que havia $100 \%$ do elemento de $\mathrm{Ag}^{0}$ (prata metálica) disperso em solução, como se observa na tabela 1 abaixo:

Tabela 1 - Análise EDX de solução de AgNPs

\begin{tabular}{|c|c|c|c|c|c|}
\hline Analyte & Result & (Std.Dev.) & Proc.-Calc. & Line & Int. (cps/uA $)$ \\
\hline $\mathrm{Ag}$ & 100.000 & $(2.101)$ & Quan-EP & $\mathrm{AgKa}$ & 3.1217 \\
\hline
\end{tabular}

Além disso, a análise obtida com o espectofotômetro da dispersão coloidal de AgNPs exibe uma banda de absorção aproximadamente em $400 \mathrm{~nm}$, confirmando que a síntese foi bem sucedida uma vez que a banda de absorção típica para as AgNPs é na região de 350 a 450 nm. As figuras 3 e 4 mostram o espectro de absorção da dispersão da solução coloidal de 
AgNPs quando utilizado estabilizador para evitar a aglomeração das nanoparticulas e sem a utilização do estabilizador.

Figura 3 - Espectro de absorção da dispersão de AgNPs (com estabilizador)

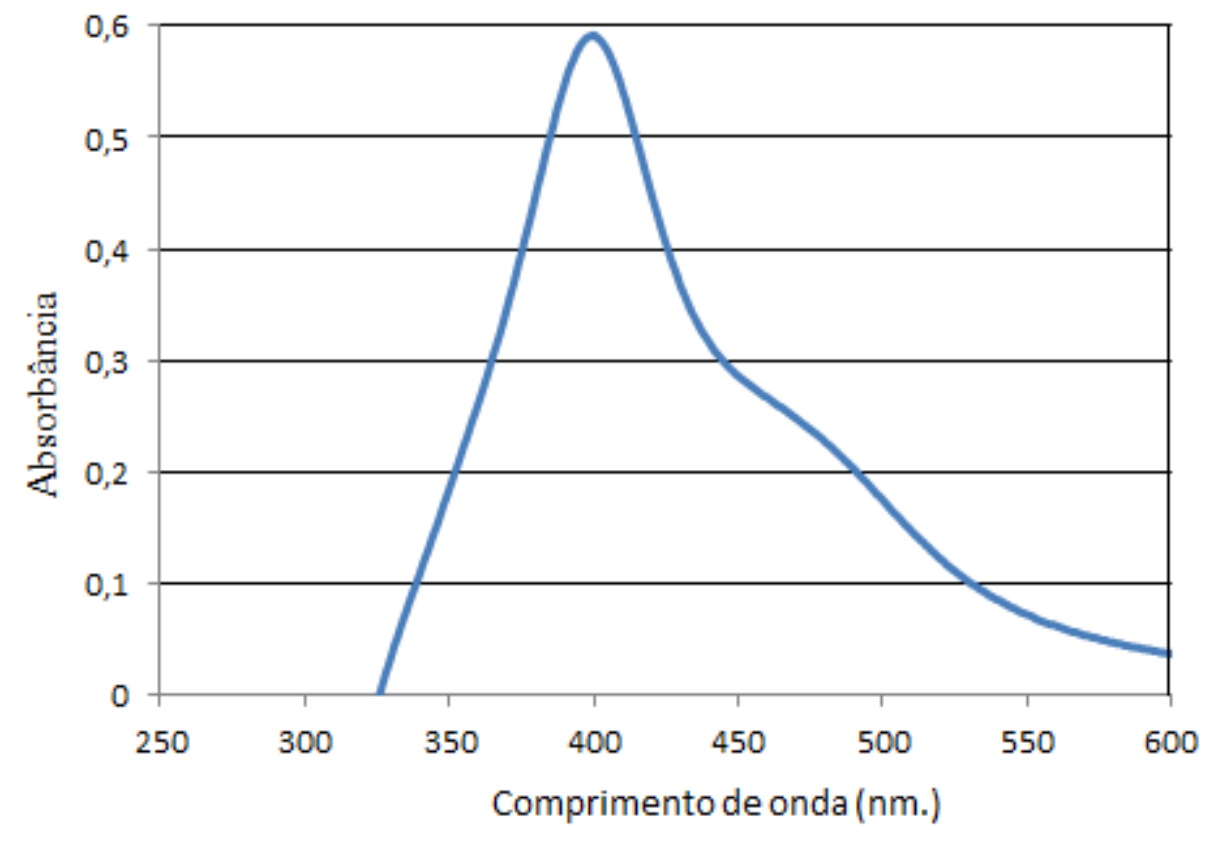

Figura 4 - Espectro de absorção da dispersão de AgNPs (sem estabilizador)

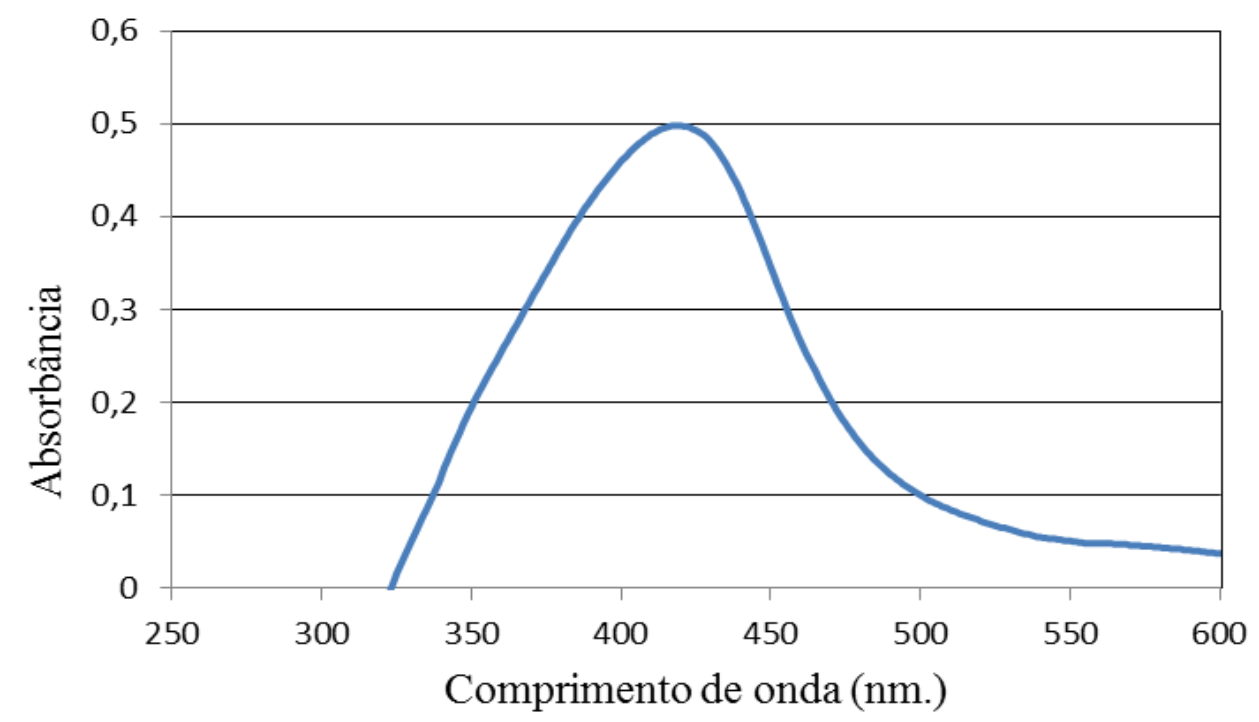




\section{CONCLUSÃO}

A preparação de sistemas bioeletroquímicos baseados em AgNPs está em auge, devido a sua capacidade de interação deste material com os bioreceptores. Além disso, a confecção de biossensores aliados a imobilização de enzimas para análise de etanol, se mostrou eficaz, os voltamogramas obtidos mostram um comportamento picos Ipa e Ipc bem definido, garantindo a reversibilidade do sistema. A imobilização das enzimas no compósito mostrou seu efeito sinérgico na sua resposta eletroquímica mostrando sua potencialidade de uso do biossensor ao monitoramento de processos.

\section{REFERÊNCIAS}

AHMAD. A.; MUKHERJEE. P.; SENAPATI. S.; MANDAL. D.; KHAN. M.I.; KUMAR. R.; SASTRY. M. (2007)Extracellular biosynthesis of silver nanoparticles using the fungus Fusarium oxysporum, Colloids Surf B Biointerf,; 28; 313-318.

CAMMANN, K;FRESENIUS, Z.; TURNER, A. P. F.; KARUBE, G.; WILSON,S. (eds.) (1987); Biosensors, Fundamentals and Applications. Oxford, University Press, Oxford.

ELIANA ALHADEFF e NINOSKA BOJORGE (2011). Graphite-Composites Alternatives for Electrochemical Biosensor, Metal, Ceramic and Polymeric Composites for Various Uses, Dr. John Cuppoletti (Ed.), ISBN: 978-953-307-353-8, InTech, DOI: 10.5772/17957. Available from: http://www.intechopen.com/books/metal-ceramic-andpolymeric-composites-for-various-uses/graphite-composites-alternatives-forelectrochemical-biosensor

GARCIA, M. B. F.; (2004); Imobilização de enzimas em materiais nanoestruturados: atividade, estabilidade e aplicação de peroxidase imobilizada em bicamadas lipídicas e nanopartículas poliméricas; Florianópolis, SC.

KATZ, E.; WILLNER , I.;( 2004) Electroanalysis , 16 , 19 - 42.

SANTANA A. C.; SOUTHGATE E. F.; MENDES J.P.B.G.; DWECKJ.; ALHADEFF E.M.; BOJORGE RAMIREZ.N. I.; (2014), Characterization of an HRP/AOX polyaniline graphite composite biosensor J. Electrochem. Sci. Eng., 4, 165 175 , ISSN $1847 \neg 9286$.

WANG , J.; ( 2000 ) From DNA Biosensors to Gene Chips. Nucleic Acids Research, v.28, n.16, p.3011-3016 